\title{
A NECROPOLÍTICA AMBIENTAL BOLSONARISTA PELAS IMAGENS DE PORTAIS NOTICIOSOS NO INSTAGRAM ${ }^{1}$
}

\author{
THE BOLSONARIST ENVIRONMENTAL NECROPOLITICS FOR \\ NEWS PORTAL IMAGES AT INSTAGRAM
}

\author{
Rafael Sbeghen Hoff² e Janaíne Guimarães dos Santos ${ }^{3}$
}

\section{RESUMO}

O presente trabalho pretende refletir sobre a relação entre imagem e texto, que são dispostas no jornalismo digital, a partir da análise de cinco perfis noticiosos do Instagram, entre janeiro de 2018 e junho de 2020. As imagens são analisadas pelo em seu conteúdo, relação com os caracteres sobrepostos e na legenda, bem como a partir de seus intradiscursos e interdiscursos. A partir de métodos de pesquisa para a internet (FRAGOSO; RECUERO; AMARAL, 2011) e também da pesquisa qualitativa com texto, imagem e som (BAUER; GASKELL, 2008), foi recortado sobre o objeto empírico o conteúdo relacionado à editoria de Jornalismo Ambiental, com ênfase sobre pautas relacionadas à Amazônia e Meio Ambiente. Os resultados apontam para imagens fotográficas genéricas, muitas vezes sem identificação de origem e/ou autoria, utilizadas para ilustrar o tema ou causar impacto. Memes, montagens e ilustrações fazem parte desse universo imagético, amplamente utilizadas junto a um jornalismo opinativo, que alia denúncias que acabam por caracterizar uma necropolítica ambiental bolsonarista em curso. O trabalho foi realizado como Pesquisa de Iniciação Científica entre 2020 e 2021, com apoio da Fundação de Amparo à Pesquisa do Amazonas (FAPEAM) e Universidade Federal do Amazonas.

Palavras-chave: jornalismo ambiental, discurso, imagem, fotografia, Instagram.

\section{ABSTRACT}

This work intends to reflect on the relationship between image and text, which are arranged in digital journalism, based on the analysis of five Instagram news profiles, between January 2018 and June 2020. The images are analyzed by their content, relationship with the superimposed characters and in the caption, as well as from their intradiscourses and interdiscourses. From research methods for the internet (FRAGOSO; RECUERO; AMARAL, 2011) and also from qualitative research with text, image and sound (BAUER; GASKELL, 2008), the content related to the Enviromental Journalism editorship was cut out on the empirical object, with emphasis on agendas related to the Amazon and the Environment. The results point to generic photographic images, often without identification of origin and/or authorship, used to illustrate the theme or make an impact. Memes, montages and illustrations are part of this imagery universe, widely used together with an opinionated journalism, which combines accusations that end up characterizing an ongoing bolsonarist environmental necropolitics. The work was carried out as Scientific Initiation Research between 2020 and 2021, with support from the Amazonas Research Support Foundation (FAPEAM) and the Federal University of Amazonas.

Keywords: enviromental journalism, discourse, image, photography, Instagram.

1 Texto resultado de Pesquisa de Iniciação Científica desenvolvida pelos autores entre 2020 e 2021 na Universidade Federal do Amazonas, com bolsa de pesquisa da Fundação de Amparo à Pesquisa do Amazonas - FAPEAM.

2 Jornalista, mestre em Letras e Cultura Regional, doutor em Ciências da Comunicação e Informação, professor permanente do Programa de Pós-Graduação em Comunicação da UFRR, docente da graduação em Jornalismo da UFAM, líder do Grupo de Pesquisa em Processos Imagéticos (PRIMA-UFAM) e integrante da Rede Amazoom - Observatório Cultural da Amazônia e do Caribe. E-mail: rafael.hoff@yahoo.com.br

3 Estudante de Jornalismo da UFAM, pesquisadora do Programa de Iniciação Científica (PIBIC) Imagens Amazônicas: produção, circulação e consumo imagético em perfis de notícias no Instagram (2020-2021), bolsista FAPEAM. E-mail: janagguimas@gmail.com 


\title{
INTRODUÇÃO
}

O presente artigo é derivado do relatório final e das apresentações feitas em eventos regionais e nacionais a partir dos resultados obtidos na pesquisa desenvolvida no Programa de Iniciação Científica (PIBIC-UFAM). Ele está vinculado ao Grupo de Pesquisa em Processos Imagéticos e à pesquisa Imagens Amazônicas: produção, circulação e consumo imagético em portais de notícias. Ele parte da sensibilização dos pesquisadores sobre a força e a presença ubíqua de imagens na comunicação digital contemporânea. Como aponta Juliana Fonseca,

\begin{abstract}
As imagens se combinam para dar nascimento aos conceitos, ao juízo e ao raciocínio, e assim, a construção de pensamentos. Não há pensamentos sem imagens, visto que, o pensamento é um ato inconsciente do espírito que para se tornar consciente tem necessidade de imagens e palavras. Adicionalmente, a imagem não nega o racional, mas não necessita da razão para se impor como realidade. Ela é 39 mais do que reflexo do mundo "objetivo", pois guarda em si uma subjetividade histórica. A imagem é a forma cognitiva com a qual o homem representa a essência do objeto a fim de apossá-lo e com ele operar relações, como por exemplo, construir teorias e agregar valores e significados. (FONSECA, 2016, p. 38-39)
\end{abstract}

As imagens em circulação, que constituem o imaginário sobre a Amazônia e sobre o Meio Ambiente, são impactados pela força discursiva dos meios de comunicação e, em especial, dos espaços jornalísticos. O conhecimento de mundo oferecido pelos discursos apresentados nestes espaços se impõem como uma versão da verdade, que goza de algumas prerrogativas (como o compromisso público com a verdade ou o processo técnico de verificação e checagem de dados) que institui uma aura de credibilidade ao veículo e ao conteúdo.

O texto foca sobre o estudo a respeito dos discursos imagéticos postos em circulação tendo como tema a Amazônia e Meio Ambiente, buscando entender quais são as os interesses e lugares de fala em disputa, bem como as opções comunicacionais em torno das imagens que são produzidas e/ ou consumidas sobre a região. A pergunta que norteia a pesquisa pode ser resumida em: Qual é a representação da Amazônia e do Meio Ambiente, postas em circulação em uma plataforma digital com alcance mundial pelos perfis jornalísticos brasileiros?

Os povos originários são incluídos na pesquisa a partir do entendimento que, assumindo uma tentativa de descolonizar/decolonizar o pensamento científico, estes são parte do Meio Ambiente e da natureza. Na região amazônica existem nativos, ribeirinhos, pequenos produtores rurais e muitas etnias indígenas. Dar visibilidade às diferenças, aos interesses e desejos, às necessidades e desafios dessas comunidades é aceitar que o próprio discurso entorno de uma região amazônica possui o vício de origem revelado pela busca de unificar e simplificar o que é naturalmente e empiricamente complexo. Para os cientistas que devotam energia e tempo à produção de saberes amazônicos, não há uma Amazônia, e sim Amazônias. Ademais, o conceito de Meio Ambiente também oferece uma complexidade intrínseca, uma vez que aglutina fatores físicos, químicos e biológicos em relações de 
interdependência mútua. Além dos fatores naturais, políticas públicas implementadas por agentes políticos, por meio de legislação, atuação de organizações e instituições, também integram e impactam sobre esse ecossistema. Cabe ao jornalista essa função de informar se esses direitos e deveres, não só com essas pessoas, mas também com Meio Ambiente, estão sendo atendidos da forma correta.

A cobertura de conflitos ambientais pelo Jornalismo se torna ainda mais importante, já que a defesa da cidadania e dos direitos fundamentais, em especial das chamadas "minorias", está previsto no código de ética da profissão. "Denunciar desigualdades e situações de conflito, além de objeto de interesse público, pode contribuir para o fim do arbítrio, do autoritarismo e da opressão - também são responsabilidade do jornalista" (CAMANA, 2018, p. 129-130).

Optamos metodologicamente pela Análise de Conteúdo sobre as imagens, legendas e caracteres que constituem o discurso jornalístico veiculado pelo Instagram nestes perfis analisados. A escolha de relacionar imagem e texto está vinculada à proposição teórica de Jorge Pedro Sousa:

O texto é um elemento imprescindível da mensagem fotojornalística. Embora a fotografia e texto não sejam homogêneas (o texto ocupa, geralmente, um espaço contíguo ao da fotografia, não invadindo o espaço desta, a não ser para construir mensagens gráficas), não existe fotojornalismo sem texto. (SOUSA, 2002, p. 74)

Reforçando o ideal, é válido citar o pensamento da escritora Gemma Penn (2003, p. 322): “A imagem é sempre polissêmica ou ambígua. É por isso que a maioria das imagens está acompanhada de algum tipo de texto: o texto tira a ambiguidade da imagem”. Assim, articulamos a leitura dessa relação - texto e imagem - como essencial para o entendimento dos discursos em circulação nestes espaços jornalísticos digitais.

Além disso, de acordo com a pesquisa nacional realizada pela plataforma Olhar Digital ${ }^{4}$, o Brasil é o país que mais usa redes sociais na América Latina. Cerca de $80 \%$ da população brasileira acessa os aplicativos. Também, é válido ressaltar que o consumo desse conteúdo é feito sobretudo pelo smartphone (mobile), visto que o uso do celular facilita no acesso a diversos conteúdos, inclusive os que trazem assuntos jornalísticos. As imagens técnicas e as plataformas digitais, tal como conceituam Granato et al. (2020), impactam sobre uma nova cultura de produção, circulação e consumo das informações dispostas na web:

as tecnologias digitais potencializam as relações tanto interpessoais quanto entre pessoas e organizações, que acabam por sofrer forte influência da cultura adjacente aos atores sociais presentes nesse diálogo. Isso fica nítido quando se concentra o foco do estudo para as redes sociais digitais em que os atores sociais, sejam eles pessoas ou organizações, estão muito próximos, na verdade a um “clique” de distância. (GRANATO et al., 2020, p. 2)

Com isso, buscamos identificar quais são as orientações ideológicas desses perfis noticiosos no Instagram, evidenciadas pelo tratamento dispensado ao tema Meio Ambiente. Sabe-se que o Brasil

4 Disponível em: https://bit.ly/3qLsos9 
se encontra em um cenário político bastante conturbado quando se trata de questões ambientais. $\mathrm{O}$ atual presidente Jair Messias Bolsonaro e seus colaboradores diretos têm tratado de forma negligente assuntos que dizem respeito à Amazônia e o Meio Ambiente. Mais do que isso, há uma franca política de exploração ${ }^{5}$ dos recursos naturais em detrimento das condições de vida dos povos originários e/ ou da preservação de espécies. Essa postura política e ambiental pode ser enquadrada naquilo que o filósofo Achille Mbembe chama de necropolítica, conceituada como:

soberania expressa predominantemente como o direito de matar. [...] relaciono a noção de biopoder de Foucault a dois outros conceitos: o estado de exceção e o estado de sítio. Examino essas trajetórias pelas quais o estado de exceção e a relação de inimizade tornaram-se a base normativa do direito de matar. Em tais instâncias, o poder (e não necessariamente o poder estatal) continuamente se refere e apela à exceção, emergência e uma noção ficcional do inimigo. Ele também trabalha para produzir semelhantes exceção, emergência e inimigo ficcional. (MBEMBE, 2016, p. 128)

No caso da necropolítica bolsonarista, o "inimigo" é um "fantasma comunista" que impediria o desenvolvimento econômico e social do país, com ênfase à região amazônica. O ex-Ministro do Meio Ambiente Ricardo Salles, durante a realização desta pesquisa, foi protagonista de diversas ações que corroboram esse pensamento e postura política. Ricardo Salles administrou de maneira truculenta a pasta, alvo de críticas por parte da mídia e de especialistas no assunto, deixando o cargo em 23 de junho de 2021. A voz da essa esfera política, colocada em evidência pelos espaços midiáticos, é proposto pelo autor Felipe Pena (2005, p. 29) como fundamental para a constituição de uma cultura e leitura de mundo na atualidade: "A mídia (a imprensa como parte dela) assumiu a privilegiada condição de palco contemporâneo do debate público". Tomando essa perspectiva, procuramos investigar quais vozes são "ouvidas” pela mídia e inferimos quais são silenciadas.

É notório, por meio do engajamento, o encontro entre Jornalismo Ambiental e as múltiplas facetas que incorporam esse segmento. O Jornalismo Ambiental, atualmente, assume um caráter construtivo e essencial para a sociedade. De maneira destruidora e soberana, a sociedade vive em uma guerra que de um lado encontra o desenvolvimento calcado no capitalismo selvagem e do outro a sustentabilidade (social, ambiental, econômica). Por vezes, submetidos às lógicas capitais do mercado e da concorrência, reféns do capital privado para a sustentabilidade econômica de seus negócios, os veículos de comunicação e seus espaços jornalísticos têm propagando discursos capitalistas e desenvolvimentistas liberais que tentam "mascarar" a destruição da natureza em nome de uma soberania humana, como se os seres humanos fossem externos, maiores ou autônomos ao restante do planeta e seu equilíbrio. Não é possível falar de ecossistema midiático na região amazônica sem levar em conta a percepção e discursos em circulação que tomam o Meio Ambiente como eixo central.

5 Tal como corrobora a notícia divulgada pelo site G1 sobre a postura do vice-presidente General Heleno a respeito dos garimpos em regiões de proteção ambiental na Amazônia. Disponível em: https://bit.ly/331z39e 
Isso mostra a importância de maior compreensão sobre quais são as atribuições desses jornalistas na hora de entregar conteúdos para população. Para Bueno (2007), existem diferentes funções a serem exercidas nesse segmento:

\begin{abstract}
A função informativa preenche a necessidade que os cidadãos têm de estar em dia com os principais temas que abrangem a questão ambiental, considerando o impacto que determinadas posturas, processos e modelos têm sobre o meio ambiente e, por extensão, sobre a sua qualidade de vida. No caso da função pedagógica, essa diz respeito à explicitação das causas e soluções para os problemas ambientais e à indicação de caminhos para a superação dos problemas ambientais. Já a função política tem a ver com a mobilização dos cidadãos para fazer frente aos interesses que condicionam o agravamento da questão ambiental. (BUENO, 2007a, p. 35-36)
\end{abstract}

Assim, procuramos observar e analisar os discursos imagéticos empregados pelo Jornalismo em plataformas de compartilhamento e interação social (Instagram), com vistas a descrever as imagens que constituem o imaginário social a respeito da Amazônia e do Meio Ambiente. Além disso, como espaço de disputas, procuramos identificar as tensões e os lugares de fala ocupados por quem protagoniza as histórias reportadas, bem como silenciamentos impostos às múltiplas possibilidades abrangidas pelo conceito Amazônia.

\title{
DESENVOLVIMENTO
}

A pesquisa desenvolvida no Programa de Iniciação Científica utilizou os Métodos de Pesquisa na Internet (FRAGOSO; AMARAL; RECUERO, 2011), e a Pesquisa Qualitativa com Texto e Imagem, Análise do Discurso e Análise de Conteúdo (BAUER; GASKEL, 2008) para extrair do objeto empírico elementos que subsidiassem as inferências e elucubrações.

O objeto empírico é constituído pelas postagens de cinco perfis noticiosos no Instagram: Portal R7, Mídia Ninja, Nexo Jornal, G1 e Amazônia Real, no período de 2018 até o primeiro semestre de 2020. O corpus da pesquisa incide em dois recortes temporais, o primeiro é o período de 2018 em que a presidência de Michel Temer teve curso e o segundo é do presidente, Jair Messias Bolsonaro (2019-2020). Os perfis foram selecionados a partir de uma busca empírica na própria plataforma por portais de notícias e/ou perfis noticiosos que tratassem sobre questões ambientais e amazônicas, numa espécie de flaunerie que resultou nessa coleção. Após o levantamento do corpus, são implementadas análises de conteúdo das imagens e vídeos como documentos de pesquisa (LOIZOS, 2008) e também Análise de Discurso (GILL, 2008) com o intuito de identificar qual é o lugar de fala, formações discursivas, interdiscursos, intradiscursos e silenciamentos nestas postagens.

De acordo com a escritora Rosalind Gill (2008, p. 245), 
Análise do discurso é o nome dado a uma variedade de diferentes enfoques no estudo de textos, desenvolvida a partir de diferentes tradições teóricas e diversos tratamentos em diferentes disciplinas. O que essas perspectivas partilham é uma rejeição da noção realista de que a linguagem é simplesmente um meio neutro de refletir, ou descrever o mundo, e uma convicção da importância central do discurso na construção da vida social.

Como descreve Michel Pechêux, outro teórico da Análise do Discurso, ampliando a pertinência dos estudos sobre esse tema,

\begin{abstract}
Em história, em sociologia e mesmo nos estudos literários, aparece cada vez mais explicitamente a preocupação de se colocar em posição de entender esse discurso, a maior parte das vezes silencioso, da urgência às voltas com os mecanismos da sobrevivência; trata-se para além da leitura dos Grandes Textos (da Ciência, do Direito, do Estado), de se pôr na escuta das circulações cotidianas, tomadas no seu ordinário do sentido. (PECHÊUX, 2002, p. 48)
\end{abstract}

Amparada nos pressupostos descritos acima, foi realizada a análise do discurso a partir das postagens nos respectivos perfis com o intuito de elencar qual é o processo e como se dá a entrega desse conteúdo jornalístico no meio digital.

Sabe-se que a internet é um meio de comunicação que conta principalmente com a entrega de conteúdo a partir de imagem, texto e som. Mediante a isso, a coleta do corpus foi realizada através do método de pesquisa qualitativa, que consiste na busca da compreensão do comportamento de cada perfil do Instagram dentro da editoria de Jornalismo Ambiental, estudando, assim, suas particularidades. É notório também que a população recebe grande influência desses meios de comunicação na internet, como refere Loizos (2008, p. 138): “O mundo em que vivemos é crescentemente influenciado pelos meios de comunicação, cujos resultados, muitas vezes, dependem de elementos visuais. Consequentemente, "o visual” e "a mídia" desempenham papéis importantes na vida social, política e econômica."

Das palavras de Loizos (2008) depreende-se que esses meios de comunicação têm uma enorme facilidade em fazer com que seus internautas sejam atraídos para determinados assuntos, já que a imagem é uma ferramenta de grande potencial para isso. Além do papel de informar, cabe ao jornalista as funções de educar midiaticamente e também de ofertar a equidade de vozes e interesses em disputa no tecido social. Isso não quer dizer isenção, uma falácia superada nas teorias jornalísticas desde a década de 1960, mas o atendimento a uma concepção de cidadania, dignidade humana e justiça que transcendem posicionamentos partidários ou ideológicos (expressos pelas linhas editoriais) em nome do Estado Democrático de Direito e da humanidade.

Para tanto, os conteúdos foram classificados segundo as categorias descritas a seguir, como forma de organizar e aglutinar conteúdos de mesma qualidade. São elas:

- Meio Ambiente e Amazônia: agrupa o segmento de postagens que tratam especificamente sobre meio ambiente, povos originários, povos indígenas, etnias, tribos, cultura amazônica, ribeirinhos, territórios e espaços, biopirataria, crime ambiental, queimadas, entre outros; 
- Jornalismo Ambiental: aglutina pautas associadas às questões educacionais, de preservação ambiental, tutoriais, explicativas ou de valor científico (promoção e divulgação de ciência \& tecnologia);

- Política e Meio Ambiente: são reunidas as pautas publicadas que tratam sobre Ministério do Meio Ambiente, ministro Ricardo Salles, presidente Jair Bolsonaro, presidente Michel Temer - de forma geral agentes públicos ocupando algum papel social no contexto - governo ou que tratem de maneira direta/ indireta de órgãos e instituições governamentais (ex: ICMBio, Ibama, INPA, Funai, Polícia Federal, etc.).

Essas categorias foram criadas a partir dos encontro dos pesquisadores com os conteúdos postados nos perfis noticiosos no Instagram. Os autores reconhecem que uma mesma matéria (conteúdo jornalístico) poderia ser classificada em mais de uma categoria, mas optaram por não realizar essa duplicidade com o intuito de facilitar o processo analítico.

A seguir, procuramos apontar elementos contextuais sobre o corpus analisado, procurando compilar alguns dados para uma melhor compreensão sobre o universo da pesquisa e a relevância dos resultados obtidos.

Gráfico 1 - Contagem de Título por Perfil

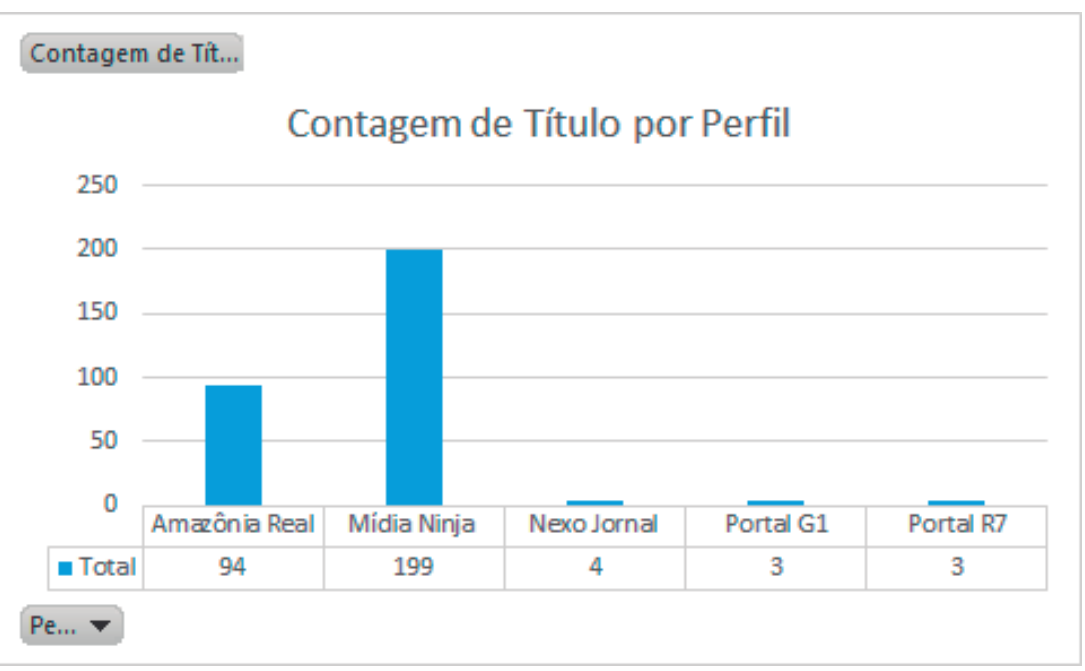

Fonte: os autores

O gráfico acima foi constituído por colunas, que mostram o número de postagens sobre Amazônia e Meio Ambiente em cada perfil, seguindo uma ordem alfabética para os perfis analisados. Seguindo a ordem em que os dados foram postos no gráfico, o Amazônia Real contabilizou o número de 94 postagens ao longo de toda pesquisa, em sequência o perfil Mídia Ninja se sobressaiu a todos os outros e totalizou 194 publicações, o Nexo Jornal ofereceu apenas 4 e os dois últimos, Portal G1 e o Portal R7, apenas 3 publicações cada.

Percebemos, com estes números, uma preocupação maior dos dois veículos de comunicação Amazônia Real e Mídia Ninja - com as temáticas elencadas para esse estudo. Quantitativamente, há um indício de posicionamento dos dois veículos em manter foco e publicizar conteúdos relacionados à temática ambiental e amazônica no período entre 2018 e 2020. Vale ressaltar que os dois perfis 
correspondem a agências independentes de notícias, ou seja, que não dependem de anúncios privados ou verbas públicas para a sustentação econômica das organizações. Esse fator permite, como expressam os números, uma maior liberdade na definição das pautas e/ou abordagens sobre os temas e acontecimentos transformados em notícias. O mesmo não acontece com Portal G1 (vinculado à Rede Globo) Portal R7 (vinculado ao sistema Record de comunicação) e Nexo Jornal.

A seguir, com o intuito de ilustrar os discursos e conteúdos publicizados pelos perfis que compõem este estudo, elencamos uma postagem de cada um dos perfis, ainda que durante a pesquisa se tenha aplicado as técnicas de análise sobre um corpus maior. Esse recorte, apresentado aqui, procura atender aos limites (número de páginas) apontado pelas diretrizes dos autores desta publicação. A seleção desse material se deu a partir da relevância / capacidade de síntese / adequação dos conteúdos às propostas de análise elencadas para a pesquisa. Elas não encerram a discussão ou conseguem contemplar em profundidade, sempre, todos os aspectos analisados e investigados, mas como uma coleção de textos, procuram ilustrar um discurso mais amplo, profundo, que revela lugares de fala e formações ideológicas.

As análises serão acompanhadas de indícios midiáticos elencados a partir de rastros digitais (BRUNO, 2012) que são acionados para uma contextualização das imagens e textos publicados. Essa relação possível, abordada nesta pesquisa como provável, toma por base a ideia de que um discurso é atravessado por outros discursos, tal como preconiza Pechêux (2002).

\section{ANÁLISE E DISCUSSÃO DOS DADOS}

\section{PERFIL MÍDIA NINJA}

O perfil Mídia Ninja (@midianinja), em geral, apresenta assuntos que tratam de política, sociedade e economia. No decurso da pesquisa, entre 2018 e o segundo semestre de 2020, foi coletado um total de 199 publicações. Dessas, foi escolhida uma imagem com a pretensão de auxiliar na demonstração e na compreensão da pesquisa.

Figura 1 - Postagem Mídia Ninja - 03/07/2018.

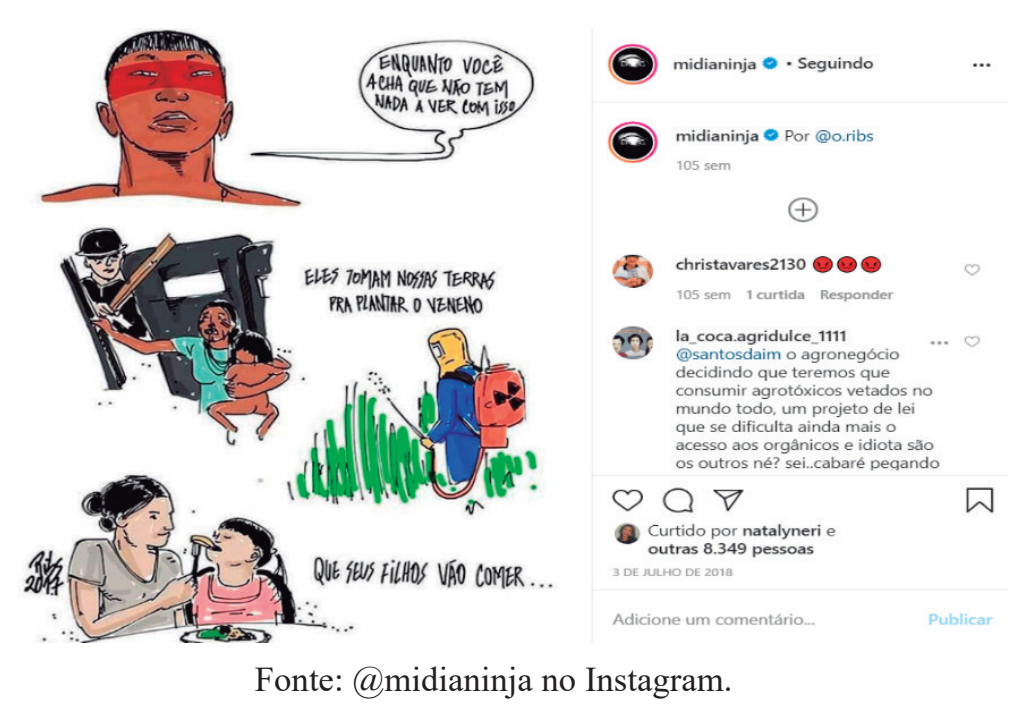


As imagens postas em circulação mostram fotografias, desenhos e frases que remetem ao descontentamento da página com o posicionamento do então presidente Michel Temer sobre os assuntos relacionados ao Meio Ambiente e Saúde Pública. Os textos, nas imagens e legendas, apresentam frases que caracterizam um pessimismo sobre o campo político, constituído pela crítica aos efeitos prejudiciais das políticas públicas desse governo e também pela crítica ao papel do Estado na preservação do meio ambiente e proteção dos povos originários.

Na figura em destaque, a arte chama atenção pela representação da cadeia produtiva dos alimentos, onde os povos originários são despejados e massacrados em nome da produção agrícola em larga escala, que conta com o apoio estatal e seus aparelhos de coerção para imprimir uma política que privilegia os interesses de poucos em detrimento das etnias indígenas. A discussão apresentada pelo perfil com a representatividade indígena, exibe na primeira frase "enquanto você acha que não tem nada a ver com isso", mostrando inicialmente uma frase dirigida à sociedade que se exime ou ignora assuntos relacionados a esses brasileiros, bem como se expressa na segunda e terceira frase "eles tomam nossas terras para plantar o veneno", "que seus filhos vão comer".

Esse discurso procura, em primeiro lugar, conclamar a sociedade branca ocidental (não indígena) à reflexão sobre o modo como os povos, a terra, os alimentos e a natureza estão interligados, em oposição à lógica extrativista e capitalista que vê o planeta como fonte de recursos a serem explorados comercialmente. Além disso, propõe uma interdependência entre os povos indígenas e não indígenas, mostrando que as políticas públicas implementadas sobre uns, refletem sobre a qualidade de vida dos outros. Daí que a esfera pública e o exercício da cidadania devem passar, necessariamente, pela alteridade.

Aqui reforçamos a pertinência de tratarmos dos povos originários no contexto do Jornalismo Ambiental. Partimos do reconhecimento que a cultura indígena não dissocia o sujeito da natureza, mas o toma como parte dela. Seja na forma de se relacionar para a subsistência, seja na forma de cultuar os elementos naturais, as culturas indígenas brasileiras estão ligadas intrinsecamente à territorialidade, ou seja, ao espaço que ocupam e os elementos naturais que conformam esse habitat, significando-os. É dessa percepção de indissociabilidade que entendemos tratar dos povos originários como elemento integrante do contexto Meio Ambiente. As mensagens publicadas pelo perfil em análise parecem corroborar esse discurso.

\section{PERFIL NEXO JORNAL}

A segunda análise, sobre a Figura 2, trata sobre o respeito à cultura indígena e os riscos da prática de apropriação cultural. Na legenda, o perfil do Nexo Jornal aponta para o conceito e explica aos leitores que a discussão foi alimentada pelo desfile da atriz Alessandra Negrini, em um ensaio de pré-carnaval, paramentada com cocar e pinturas indígenas no rosto e no corpo. 

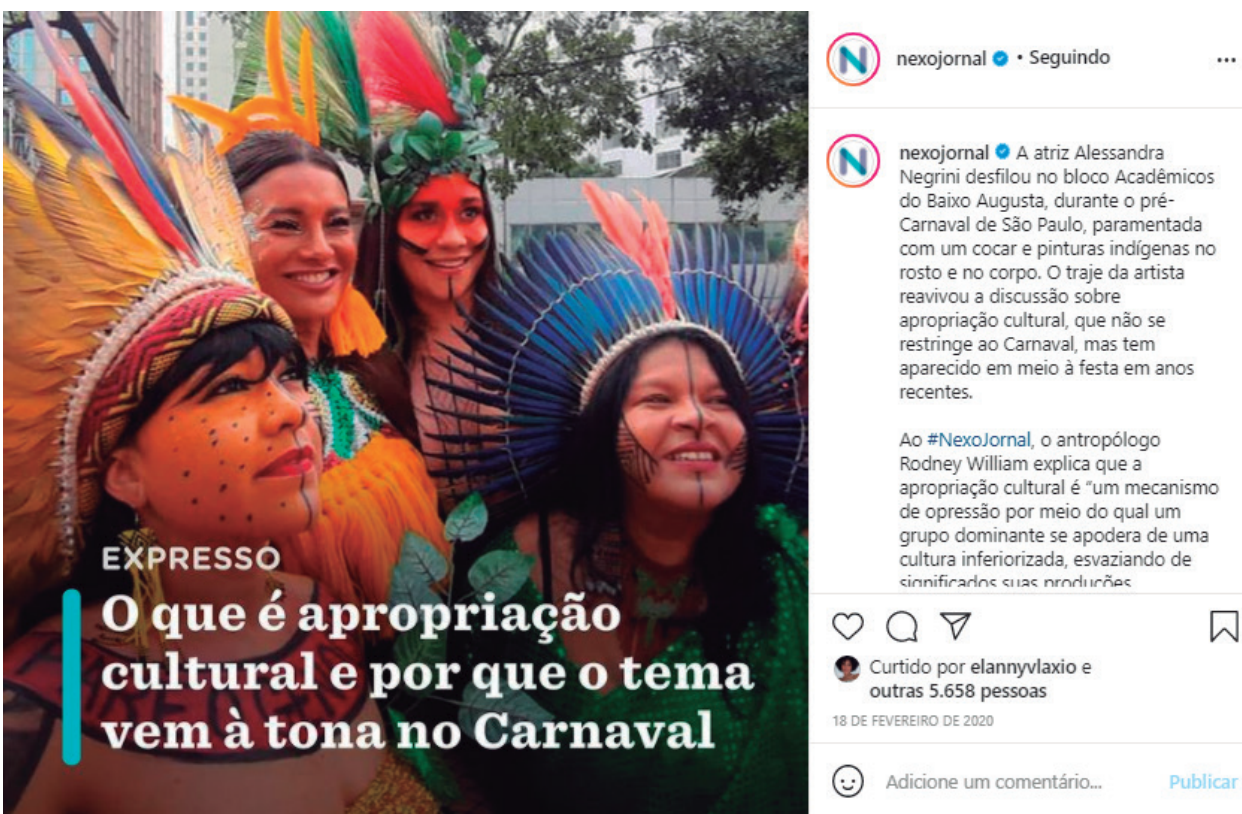

Fonte: @nexojornal no Instagram

A imagem publicada pelo Jornal Nexo em seu perfil no Instagram mostra pessoas de diferentes biotipos, incluindo pessoas consideradas brancas, paramentadas e com pinturas corporais que remetem à cultura indígena. Traz sobre a imagem, em caracteres brancos, uma chamada ao conteúdo: "O que é apropriação cultural e por que (sic) o tema vem à tona no Carnaval”. A estereotipação, o reducionismo, a interpretação equivocada, o esvaziamento de sentido dos traços culturais em uma apropriação seria, segundo o texto e o especialista - antropólogo Rodney William - apontado na legenda, uma forma de opressão. Se o conteúdo não mostra diretamente os povos indígenas, critica e educa sobre a postura das pessoas brancas a respeito da diversidade étnica nacional e sobre a postura de respeito devido às etnias indígenas e seus traços culturais. $\mathrm{O}$ discurso, então, é dirigido às pessoas brancas, e toma uma postura educativa, tal qual as funções do Jornalismo preconizadas pelos teóricos da área (KOVACH; ROSENSTIEL, 2003).

Assim, é possível inferir pelas postagens e pelo discurso imagético e textual, que o Jornal Nexo é voltado ao público branco (endereçamento da notícia), trata de questões ambientais pelo viés do Jornalismo Informativo, com nuances de educação sobre os temas pautados. Não faz críticas diretas e pouco opina fora das colunas dedicadas a esse viés. As imagens também não trazem créditos sobre seus autores, corroborando com a prática de "silenciamento" sobre os direitos autorais. Os temas abordados não são focados sobre a região amazônica e tratam dela de maneira correlata ou indireta, apontando para um lugar de fala que se constitui como nacional, abrangente, ainda que a sede do jornal esteja no Sudeste e algumas pautas que não fazem parte do escopo dessa pesquisa apontem para o interesse sobre o cotidiano da cidade de São Paulo. 


\section{PERFIL G1}

O Portal G1 no Instagram está vinculado ao portal de notícias do Grupo Globo, sediado no Sudeste. A postagem selecionada para este artigo, com o intuito de demonstrar a diversidade e abrangência do período analisado na pesquisa, é de 2019.

Figura 3 - Postagem Portal G1 - 24/09/2019.

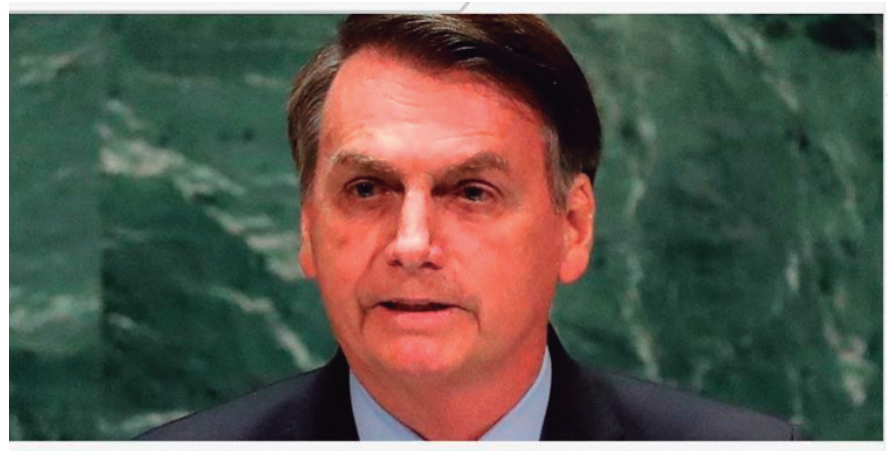

É falácia dizer que a Amazônia é patrimônio da humanidade"

JAIR BOLSONARO

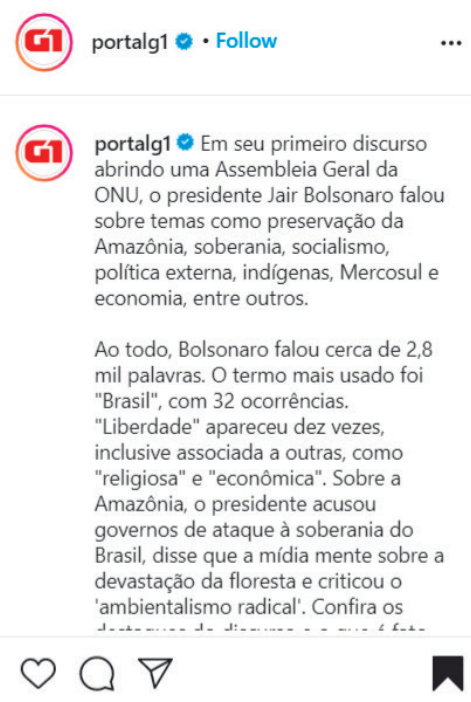

(D) Liked by nic.nr and 13,302 others SEPTEMBER 24, 2019

Fonte: @portalg1 no Instagram.

A imagem acima (Figura 3) mostra o atual presidente da república, Jair Messias Bolsonaro, e logo abaixo traz a frase "É falácia dizer que a Amazônia é patrimônio da humanidade". Abaixo dos caracteres entre aspas, a identificação de autoria da frase, atribuída ao presidente da República. A legenda descreve que o presidente, em seu primeiro discurso abrindo uma Conferência Geral da ONU, falou sobre assuntos como preservação da Amazônia, soberania, socialismo, política externa, indígenas, Mercosul e economia, entre outros. Ao todo, o governante falou cerca de 2800 palavras e entre as palavras mais faladas estão "Brasill", "Liberdade", "religiosa" e "economia". Com relação à Amazônia, segundo o perfil, o presidente acusou os governos de outras nações por ataque à soberania do Brasil, ressaltou que a mídia mente quando trata de assuntos sobre a devastação da floresta e repreendeu o "ambientalismo radical".

A imagem, em primeiro plano, mostrando o presidente Bolsonaro com a boca entreaberta, remetendo à ação de falar, remete ao registro jornalístico que busca expressar o conteúdo com um "verbo". No caso da imagem, o verbo é falar. Associando à fala destacada logo abaixo, em caracteres, o Portal G1 busca enaltecer os pontos de conflito, polêmicos e delicados na postura e na fala do presidente: acusação de crime (ambiental) sem provas. Isso, por sí só, seria suficiente para que 
qualquer Organização Não Governamental entrasse na justiça pedindo reparação por ofensa à honra (Dano Moral). Não bastasse isso, não há referência à ação governamental no sentido de preservação e/ou combate aos crimes ambientais, mas uma "defesa" do governo, em forma de acusação, opondo o governante à mídia (de modo geral e irrestrito). Neste sentido, há um discurso vazio de razão e argumentos, motivado pelos afetos, construindo um "inimigo imaginário", tal como descreve Mbembe (2018) em sua caracterização da necropolítica, a partir dessa oposição dicotômica, em que de um lado estariam o governo e seus representantes, e de outro os jornalistas e veículos de comunicação.

Se pensarmos de maneira ampla, o discurso científico é utilizado, recorrentemente pelo Portal G1, como artifício de oposição ao discurso de ódio - contra a mídia - do presidente, principalmente no que diz respeito às afirmações (sem provas) de que "não há desmatamento" ou "os índices são mal interpretados".

\section{PORTAL R7}

O Portal R7, vinculado à Rede Record, se mostram também crítica à política governamental em relação ao Meio Ambiente, mas faz uso de produção jornalística elaborada e comercializada por Agências Internacionais para colocar em circulação esse discurso.

Figura 4 - Portal R7 - 20/08/2019.
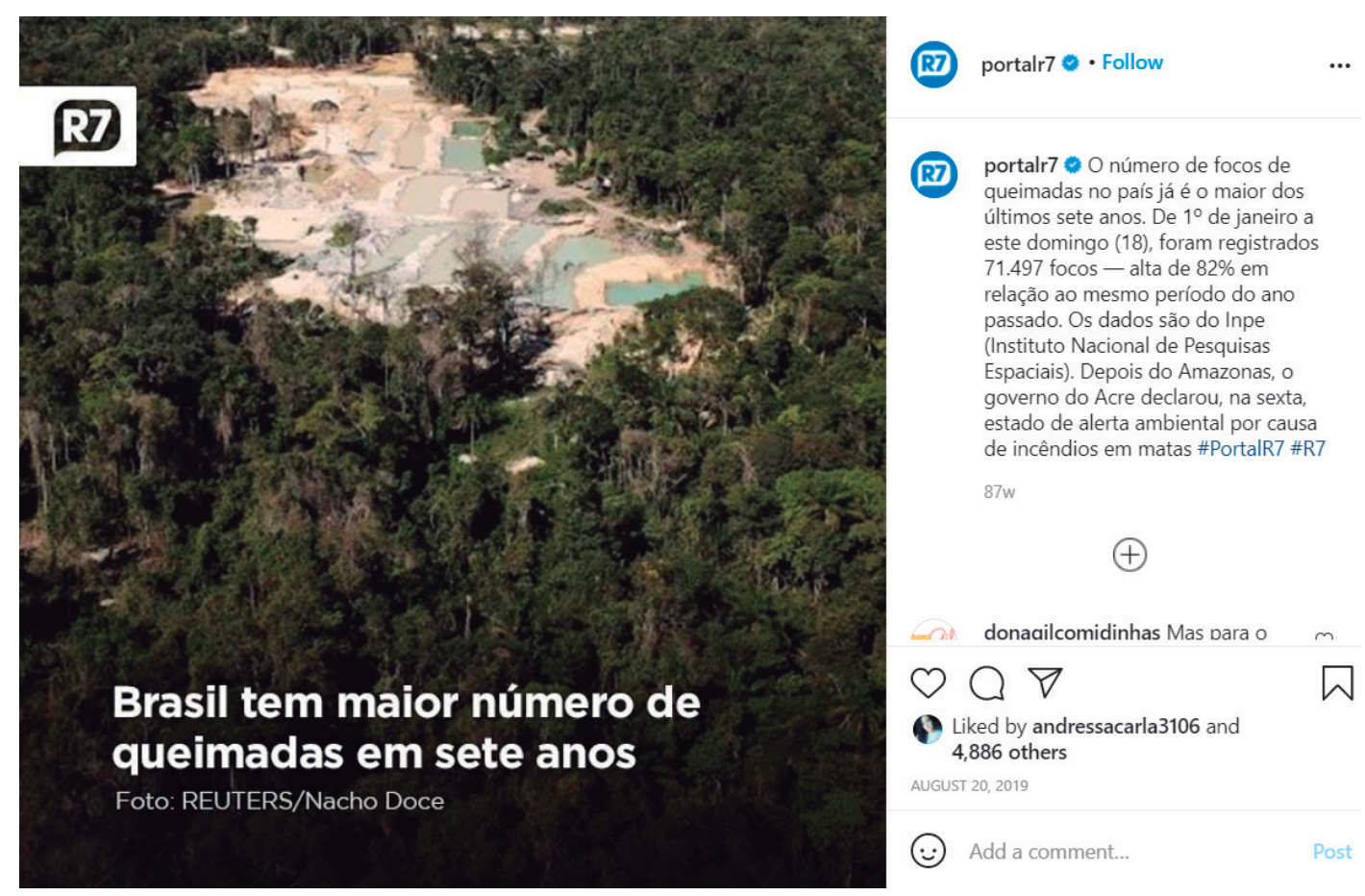

Fonte: @portalr7 no Instagram.

A imagem acima (Figura 4) mostra uma área de floresta rodeando um espaço claro, dando a ideia que a ação do homem provoca essa mudança na geografia da Amazônia. Sobre a imagem, que 
tem um ponto-de-vista superior, como se registrada de um helicóptero, avião ou drone, lê-se: "Brasil tem maior número de queimadas em sete anos". A manchete é acompanhada da fonte da imagem: "Foto: Reuters / Nacho Doce". Diferente do restante das postagens nos demais perfis, o Portal R7 identifica o autor da imagem, respeitando as determinações previstas na legislação do Direito Autoral. A legenda aponta um aumento no número de queimadas, atingindo índices recordes nos sete últimos anos (data da postagem). O discurso imagético e textual aponta para um registro, de cunho científico, reforçado pela identificação da fonte (INPE) dos dados numéricos que embasam as informações. O discurso trata a questão das queimadas, sem identificar responsáveis pelo início do fogo ou combate à ele, contribuindo para a construção de um imaginário permeado por ações sem sujeito protagonista e sem responsabilizar o governo (e suas organizações) pela manutenção e preservação dos recursos naturais brasileiros.

Esse discurso do perfil procura, com dados estatístico e científicos, se opor ao discurso de que a Amazônia (e tudo o que se refere a ela) seja uma questão de soberania nacional, tal qual defende o presidente Bolsonaro em sua fala na Organização das Nações Unidas. A defesa da soberania nacional (contra a interferência estrangeira) se apoia em um discurso ufanista do político, contraposto nesta postagem pela relação feita entre situações brasileiras que expandem seus "sintomas" aos outros países da América Latina. O veículo, então, sustenta (ainda que de maneira sutil) uma certa oposição ao governo e seus posicionamentos, mas se utiliza de eufemismos para diminuir a relação entre as ações e seus protagonistas.

\section{PERFIL AMAZÔNIA REAL}

O perfil@amazoniareal é de responsabilidade da Agência de Notícias Amazônia Real, que se identifica como independente e produtora de conteúdos voltados à realidade amazônica.

Figura 5 - Postagem Amazônia Real - 25/07/2020.
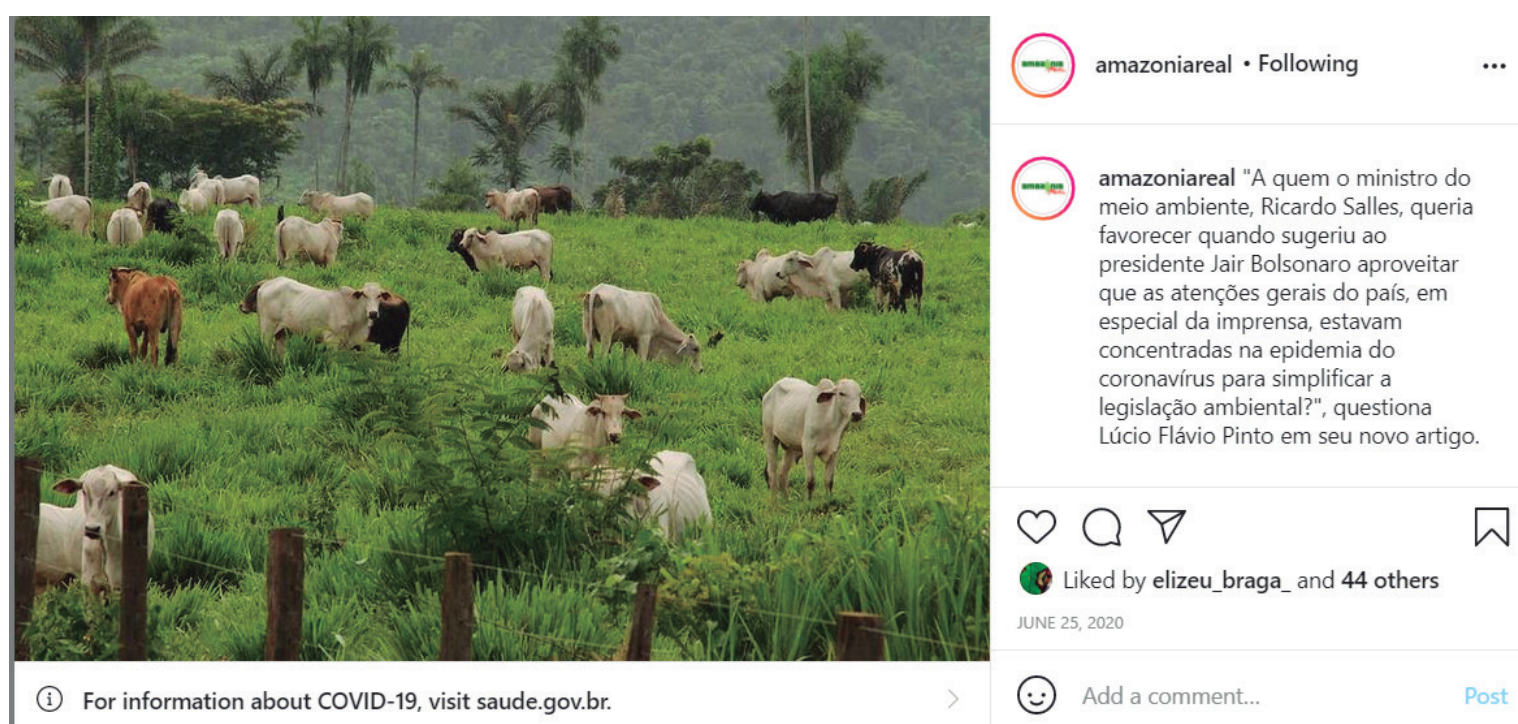

Fonte - @amazoniareal no Instagram. 
A quinta figura analisada (Figura 5) mostra um pasto com gado bovino. Sobre a própria imagem tem um link com um direcionamento para o site saúde.gov. br, que apresenta informações a respeito da pandemia de COVID-19. Ao se fazer uma observação no texto da legenda, nota-se menção ao comentário feito pelo Ministro do Meio Ambiente, Ricardo Salles, sugerindo ao presidente Jair Messias Bolsonaro e todos demais Ministros que estavam na reunião ministerial em 22 de abril de 2020, que eles aproveitassem o foco midiático na pandemia para deixarem "passar a boiada", referindo-se à implementação de políticas públicas de interesse afinado com o governo mas de pouca popularidade, tal como aprovação da exploração de terras indígenas por garimpeiros e liberação para importação e uso de agrotóxicos proibidos em outros países do mundo.

No decorrer da pesquisa do perfil Amazônia Real, entre o período de dois anos e meio (2018, 2020/01), foram reunidas 94 publicações. Nelas não constam os créditos, ou seja, o registro de quem captou as imagens ou sua origem (se foram produzidas pelo Amazônia Real). Essa ausência abre um espaço de interpretação de que todo conteúdo produzido ou é autoral ou é colaborativo (pessoas que desejam colaborar com conteúdos e enviam aos canais digitais da agência Amazônia Real). De qualquer forma, essa prática é contra-indicada pela legislação ${ }^{6}$ que se refere aos Direitos Autorais.

As publicações demonstram que o perfil apresenta o presidente Jair Messias Bolsonaro, como alguém que se lança contrário à pesquisa e que usa de artifícios como o da teorização subjetiva para tentar se esquivar de fatos que permeiam assuntos em relação ao seu governo e seus colaboradores. A Figura 4 apresenta uma crítica direta ao Ministro do Meio Ambiente Ricardo Salles e sua proposta de “aproveitar" a atenção midiática voltada para a pandemia com o intuito de aprovar as leis de interesse do governo. Essa atitude demonstra que o representante do governo admite a fiscalização (atenção) jornalística sobre suas práticas como um “poder” a ser evitado. Neste sentido, o discurso revela a atitude do político e marca a presença do veículo que a publica em uma postura contrária à governamental e seus interesses, de observação e denúncia, oposição e vigilância.

Dessa maneira, percebe-se que o discurso difundido pelo Amazônia Real é desfavorável ao atual governo, busca mostrar essas informações de modo mais contido, principalmente se for feito um comparativo ao perfil do Mídia Ninja, que trabalha de forma a fazer críticas abertas e diretas.

\section{CONSIDERAÇÕES PROVISÓRIAS}

O lugar de fala ocupado pelos veículos de comunicação varia em relação ao endereçamento das notícias, uma vez que muitos deles contam com produções jornalísticas realizadas a partir do "olhar estrangeiro", pouco se ocupam com o aspecto humanizante de incorporar personagens regionais às narrativas e mantém o texto centrado em dados científicos como postura de oposição ao discurso governamental.

6 Conforme a Lei 9.610 de 19 de fevereiro de 1998. Disponível em: https://bit.ly/3HzZ2Uj. Consultada em 28/08/2021. 
As imagens, no geral, carregam um tom opinativo que se mescla ao aspecto informativo destes perfis. Entre fotografias e graficações, a relação entre texto e imagem procura chamar a atenção para uma postura de "desconstrução" do discurso governamental a respeito das questões amazônicas, com ênfase sobre a figura do presidente da República Jair Messias Bolsonaro. Ainda que não utilizem explicitamente o termo necropolítica, essas postagens demonstram os efeitos performáticos de uma política de morte implementada pelo governo, seja dirigida aos povos originários (por omissão na defesa de seus direitos), seja voltada à fauna e flora que compõem o Meio Ambiente.

Com base nos dados levantados e nas análises implementadas ao longo da pesquisa, observa-se a importância do estudo para compreensão de como o Jornalismo tem sido produzido e disseminado no meio digital, em especial tratando de temáticas relacionadas aos conceitos-chave Amazônia e Meio Ambiente. As imagens variam de charges às fotografias, por vezes registradas no ângulo reto (plano dos olhos do fotógrafo), por vezes registradas em ângulo alto (de cima para baixo), revelando a utilização de um artefato tecnológico (drone, avião, helicóptero, satélite) alimentando o imaginário sobre os recursos envolvidos na produção do conteúdo jornalístico. Com grande visibilidade / legibilidade, essas imagens são utilizadas tanto em conteúdos caracterizados como Opinativos, quanto àqueles vinculados ao gênero Informativo ou Interpretativo (MELO; ASSIS, 2016).

Ao final das análises empregadas sobre o corpus, foi possível identificar Formações Discursiva que "negligenciam" a identificação dos autores dos crimes ambientais reportados. Não é possível fazer uma associação direta entre os posicionamentos "de direita" e "de esquerda" em relação ao Meio Ambiente, ainda que a defesa dos interesses de grileiros, garimpeiros, contra a demarcação de terras indígenas e em prol de um desenvolvimento da região amazônica deixem subentender o discurso neoliberal, que preconiza uma menor intervenção do Estado sobre a economia e a defesa dos interesses de quem já detém os modos de produção (no caso, a terra se evidencia como um elemento importante do viés econômico atrelado às questões ambientais).

O ângulo alto e as imagens de satélite utilizadas em várias postagens remete ao distanciamento, afastamento físico entre o ambiente onde a informação se dá e o consumidor desta. Tendo em vista que os canais digitais, como o caso do Instagram, podem ser acessados de qualquer parte do país por meio da conexão com a internet, essa distância e a dificuldade (inclusive pela falta de personagens e elementos mais claros da paisagem) de leitura das regiões cobertas jornalisticamente reforçam o imaginário de que a Amazônia é grande, distante, por consequência exótica e de difícil acesso.

As fotografias, em sua grande maioria, não são assinadas nem na legenda nem sobre a imagem publicada. Essa falta de reconhecimento da autoria da imagem é uma característica recorrente dos perfis jornalísticos analisados no Instagram. Textos e imagens, assim, se tornam uma espécie de "gancho" ou "chamariz" para os conteúdos. A prática fere de forma direta a legislação que trata sobre o Direito Autoral. Além disso, constrói uma aura de quem o responsável pelo texto no Instagram ou é o mesmo autor da matéria jornalística, ou não merece o reconhecimento por não ser considerado 
(pelos veículos) como um veículo de comunicação (perfil no Instagram). Em termos de qualidade, as imagens apresentam boa visibilidade / legibilidade, uso adequado das técnicas (profundidade de campo, contraste, etc.) para a permitir esse acesso ao conteúdo.

Em geral, as fotografias que não são registradas por satélite ou imagens aéreas apresentam verbo, uma característica importante para a qualidade jornalística, principalmente de Spot News, segundo a nomenclatura de Jorge Pedro Sousa (2002). Tomando que a qualidade jornalística, no que diz respeito às informações imagéticas, está associada ao impacto e à capacidade informativa, o corpus analisado mostra boa qualidade técnica e informativa em relação às imagens integrantes de conteúdos sobre Meio Ambiente e Amazônia.

O Instagram se mostra utilizado como uma "porta" ou link externo para os conteúdos publicados nos Portais de Notícias. Não há uma preocupação de publicar o conteúdo em sua íntegra, nem atender aos princípios do lead (responder às perguntas básicas: Quem? Quando? Como? Onde? Por que?) em nenhum dos perfis analisados. Há uma sobreposição entre os gêneros jornalísticos Opinativo e Informativo / Interpretativo.

A Amazônia é tratada com uma única região, caracterizada pela presença da mata e do maior manancial de água doce do mundo. Não há tratamento às particularidades geográficas e/ou populacionais. Pouco se trata, no período analisado, das pautas relativas aos povos indígenas, sendo em grande parte abordadas pelo viés educativo e científico que procura municiar o consumidor da informação de dados embasados em pesquisas ou referências bibliográficas (e seus autores). Esse tratamento reforça a perspectiva carregada do exotismo e encantamento sobre a exuberância de recursos naturais que impregnou os discursos dos viajantes europeus nas incursões pela região Norte do país. Essa perspectiva eurocêntrica, presente também nas ações e políticas de ocupação dos territórios da região Norte ao longo dos séculos, se mostra de maneira velada e sutil nas construções imagéticas e textuais dos perfis analisados.

O Jornalismo, em resumo, se mostra um espaço de embate entre legitimidades e visibilidades, mas continua sujeito à reverberação dos estereótipos construídos historicamente sobre a região e a população que aqui habita. A pesquisa, em suma, aponta para lacunas e potencialidades que merecem um tratamento acadêmico em sala de aula, principalmente no que diz respeito à formação de jornalistas na região amazônica. Marcar, desconstruir e analisar estes pontos contribui para a formação crítica sobre a ética, a prática e os limites da atuação jornalística. Além disso, atiçam a discussão sobre a qualidade jornalística e as implicações sobre o cotidiano e a vida das pessoas historicamente invisibilizadas na mídia produzida e gerenciada a partir do Sudeste brasileiro.

\section{REFERÊNCIAS}

BAUER, Martin W.; GASKELL, George. Pesquisa qualitativa com texto, imagem e som: um manual prático. 7. ed. Petrópolis: Vozes, 2008. 
BRUNO, Fernanda. Rastros digitais sob a perspectiva da teoria ator-rede. In revista Famecos: mídia, cultura e tecnologia. V. 19, n. 3, set/dez 2012. Disponível em: https://bit.ly/331BAjK. Consultada em: 25 mar. 2018.

BUENO, W. C. Jornalismo Ambiental: explorando além do conceito. Desenvolvimento e Meio Ambiente. Editora UFPR. n. 15, jan. /jun. 2007a.

CAMANA, Ângela. Conflitos ambientais: uma pauta central para o jornalismo. p. 129-130. Disponível em: https://bit.ly/3EUvI9r

FONSECA, Juliana Martins. Paisagens e imagens amazônicas: os caminhos do imaginar, olhar e sentir. Dissertação de mestrado apresentada ao Programa de Pós-Graduação do Departamento de Geografia da Universidade Federal de Minas Gerais. Belo Horizonte, 2016. Disponível em: https:// bit.ly/3qIvnBA.

FRAGOSO, Suely; RECUERO, Raquel; AMARAL, Adriana.1 Métodos de pesquisa para internet. Porto Alegre: Sulina, 2011.

GILL, Rosalind. Análise de discurso. P. 245. In BAUER, Martin W.; GASKELL, George. Pesquisa qualitativa em som, imagem e texto: um manual prático. 7. ed. Petrópolis: Vozes, 2008.

GRANATO, Mariany Schievano; ANDRELO, Roseane; BRUMATTI, Vitor; ALMEIDA, Fernanda. As competências comunicacionais e os profissionais da comunicação: um estudo exploratório. In Revista Comunicação e Informação. v. 22. p. 1-16. Goiânia: Online, 2019. Disponível em: https:// bit.ly/3JEDNm5 .

KOVACH, Bill; ROSENSTIEL, Tom. Os elementos do jornalismo - O que os jornalistas devem saber e o público deve exigir. São Paulo: Geração Editorial, 2003.

LOIZOS, Zé. Análise de fotografias. p. 138. In BAUER, Martin W.; GASKELL, George. Pesquisa qualitativa em som, imagem e texto: um manual prático. 7. ed. Petrópolis: Vozes, 2008.

MBEMBE, Achille. Necropolítica: biopoder, soberania, estado de exceção, política de morte. In Revista Arte \& Ensaio. Trad. de Renata Santini. N-1 Edições, 2018. 
MELO, José Marques de; ASSIS, Francisco de. Gêneros e formatos jornalísticos: um modelo classificatório. In Revista Brasileira de Ciências da Comunicação. v. 39, n. 1. p. 39-56. São Paulo: Intercom, 2016. Disponível em: https://bit.ly/3sWplA0. Consultado em 01/11/2021.

PECHÊUX, Michel. O discurso: estrutura ou acontecimento. 3. ed. Campinas: Pontes, 2002.

PENA, Felipe Pena. Teoria do jornalismo. 2. ed. São Paulo: Editora Contexto, 2005.

PENN, Gemma. Análise semiótica de imagens paradas. p. 322. In BAUER, Martin W.; GASKELL, George. Pesquisa qualitativa em som, imagem e texto: um manual prático. 7. ed. Petrópolis: Vozes, 2008.

SOUSA, Jorge Pedro. Fotojornalismo. Uma introdução à história, às técnicas e à linguagem da fotografia na imprensa. Porto. 2002. Disponível em: https://bit.ly/3JEFTT9. Consultado em 02/09/2019. 